DOI 10.37882/2223-2974.2020.11.32

\title{
ПРОБЛЕМЫ РЕСОЦИАЛИЗАЦИИ ЖЕНЩИН, ОСВОБОДИВШИХСЯ ИЗ МЕСТ ЛИШЕНИЯ СВОБОДЫ (ИЗ ОПЫТА РАБОТЫ В СПБ ГБУ «КРИЗИСНЫЙ ЦЕНТР ПОМОЩИ ЖЕНЩИНАМ»)
}

\section{PROBLEMS OF RESOCIALIZATION OF WOMEN RELEASED FROM PRISON (FROM WORK EXPERIENCE IN THE "CRISIS CENTER FOR HELPING WOMEN" (ST. PETERSBURG))}

\section{A. Timoshenko}

Summary: Tthe article analyzes the main problems of social adaptation of women, former convicts; approaches to social rehabilitation of women with criminal experience by means of social service organizations are described; the issues of social adaptation of women former convicts of different ages, criminal experience, suffering from socially significant diseases, drug addicts are raised.

Keywords: resocialization of women former convicts, prevention of recidivism, social work with former convicts, crisis center for women (Saint Petersburg city)
$\mathrm{B}$ настоящее время государством уделяется большое внимание мерам по усилению борьбы с преступностью и предупреждению рецидива преступлений, поэтому проблема ресоциализации, социальной реадаптации и реабилитации лиц, освободившихся из учреждений уголовно-исполнительной системы (далее УИС), приобретает особую значимость.

Основная планомерная работа по предупреждению совершения осужденным уголовных правонарушений развернута в момент отбывания уголовного наказания в исправительном учреждении. Одним из важных элементов этого этапа работы по предупреждению рецидива выступает изоляция от общества с применением основных средств исправления (статья 43 УК РФ, статья 9 УИК РФ).

Несмотря на большую реабилитационную и воспитательную работу, проводимую в пенитенциарных учреждениях, значительное число женщин, освободившихся из мест лишения свободы, сталкиваются с трудностями социальной адаптации.

Женщины наиболее остро чувствуют и переживают существующую напряженность, социальное неблагополучие, конфликтность, более восприимчивы и уязвимы.

Необходимость повышенного внимания к женщи-
Тимошенко Анжела Анатольевна старший преподаватель, Университет ФСИН России, г. Санкт-Петербург AkrzA2017@yandex.ru

Аннотация: В статье анализируются основные проблемы социальной адаптации женщин, освободившихся из мест лишения свободы. Описываются подходы к социальной реабилитации женщин с криминальным опытом средствами организаций социального обслуживания. Поднимаются вопросы социальной адаптации женщин разного возраста, криминального опыта, страдающих социально значимыми заболеваниями, наркозависимых.

Ключевые слова: ресоциализация женщин, отбывших уголовное наказание, профилактика рецидивных преступлений, социальная работа с бывшими осужденными, Кризисный центр помощи женщинам (г. Санкт-Петербург)

нам, освободившимся из учреждений УИС, обусловлена рядом объективных и субъективных причин. К объективным причинам следует отнести разрыв социальных связей, отсутствие жилой площади, работы, документов, удостоверяющих личность, наличие инвалидности, социально опасных заболеваний, достижение пенсионного возраста.

Субъективные причины связаны с особенностями психологии женщин, вступивших в конфликт с законом. Асоциальные установки, пренебрежение общественными интересами, психологическое принятие криминального поведения, недоверие к государственным структурам, «выученная беспомощность», неуверенность в себе и в своем социальном положении, будущем, неудовлетворенность настоящим.

Профилактическую работу с женщинами, отбывшими уголовное наказание, осуществляют организации социального обслуживания (статья 2 федерального закона от 23 июня 2016 года № 182-Ф3 «Об основах системы профилактики правонарушений в Российской Федерации»).

Профилактическая работа с данной категорией получателей социальных услуг не является основным направлением их деятельности. 
Отказ от совершения преступлений является побочным результатом социальной работы, вследствие привития и закрепления социальных, психологических установок личности на законопослушный образ жизни.

Социальная работа с женщинами, освободившимися после отбывания уголовного наказания, носит специфический характер, и организуется в рамках индивидуальной программы социальной реабилитации на основании статьи 15 федерального закона от 28 декабря 2013 года № 442-Ф3 «Об основах социального обслуживания граждан в Российской Федерации».

На протяжении нескольких лет сотрудниками специализированного отделения социальной реадаптации Санкт-Петербургского ГБУ «Кризисный центр помощи женщинам» (далее - Кризисный центр, центр) проводился анализ наиболее успешных стратегий работы с женщинами, попавшими в сферу действия правосудия и обратившимися в центр за социальной помощью.

Опыт работы в Кризисном центре позволил автору сформулировать отличительные особенности реадаптации женщин в начальный период восстановления жизни на свободе.

Наиболее комфортный временной период социальной адаптации длится от 3 месяцев до 1 года и зависит от криминологической характеристики преступного опыта и биологического возраста женщины.

Женщины в возрасте 20-30 лет быстрее адаптируются в социуме, у них высокие шансы найти работу, они спокойнее воспринимают жизненные изменения.

К возрасту 35-42 лет женщинам сложнее трудоустроиться, активно проявляются болезни, являющиеся следствием беспорядочного образа жизни в юности. Некоторые женщины этого возраста стремятся вновь завести семью, родить еще детей, замещая ими душевные переживания от лишения родительских прав.

В возрасте 45-55 лет осознание собственных проблем и потребностей женщин хорошо сформировано. Часто у клиенток есть взрослые дети, которые оказывают им поддержку, в том числе материальную, но не стремятся проживать с ними на одной территории.

Опыт показал, что наиболее эффективно выстраиваются отношения между клиенткой и социальным работником в период месяца-двух после освобождения из колонии, когда женщина полна решимости изменить свою жизнь, не восстановила связи с преступным окружением, стремится трудоустроиться.

Другой пример эффективного общения - это об- ращение за помощью в связи с конкретным запросом: консультация по восстановлению родительских прав, быстрое трудоустройство, помощь в лечении от наркомании и др.

Криминологическая характеристика преступного опыта накладывает свой отпечаток на встраивание женщины в современные социальные процессы. Так, убийцы, лица, совершившие умышленное причинение тяжкого вреда здоровью, разбойное нападение и, находившиеся длительное время в условиях изоляции, на первом этапе общения с трудом воспринимают необходимость перестраивать свою жизнь. Однако, затем они достаточно стабильны в своих достижения и обращаются вновь только с конкретной целью или запросом.

Мошенники практически не обращаются за помощью в адаптационный период или их интересует материальная поддержка и иные бесплатные возможности конкретного государственного учреждения, например, праздники для детей клиентов, проводимые в Кризисном центре.

Наиболее уязвимыми к меняющимся условиям жизни оказываются наркозависимые женщины. Так, из 73 женщин, принятых в Кризисный центр на социальное сопровождение в 2019 году, 70\% наркозависимые женщины.

Специалисты, работавшие с наркозависимыми клиентами, замечают, что психическое развитие их личности останавливается в момент начала употребления наркотических средств, в связи с чем установление в доверительном разговоре с женщиной примерного возраста первого и последующего употребления наркотиков может подсказать без психологического скрининга степень зрелости и восприятия событий конкретным человеком.

Наркозависимые женщины имеют слабое волевое ядро личности. психика их негибка. На продуктивность общения влияет состояние здоровья, ослабленного борьбой с сопутствующими заболеваниями, гепатитами, ВИЧ-инфекцией. Процесс их ресоциализации и трудоустройства часто затягивается.

Автором была обобщена практика работы специалистов Кризисного центра, позволившая выделить основные проблемы женщин на период адаптации. Данная работа проводится в рамках пяти направлений оказания социальных услуг.

\section{А) Социально-бытовые вопросы}

Большинство женщин за период нахождения в колонии утрачивают навыки адаптации. Специалисты отделения помогают наработке (или восстановлению) навыков 
адаптации к жизни в современном обществе. Основная задача этого этапа - научить женщину самостоятельно решать трудности бытового характера в рамках социально-одобряемого поведения.

Специалист проводит индивидуальную беседу с целью установления контакта, в ходе которой поднимаются вопросы о предшествующей жизни, уточняется опыт вовлеченности в преступную среду, устанавливаются потребности и проблемы настоящего состояния женщины. Специалистом фиксируются слабые места в структуре личности. На этом этапе происходит выработка и согласование с клиентом примерного плана помощи. Очень важно на этом этапе общения, чтобы желание изменений исходило от самой женщины, недавно освободившейся из мест лишения свободы.

В ходе последующих встреч разговор идет о предпринятых шагах, опрос о сложностях и успехах в ходе самостоятельного решения проблемы. Специалист доводит до клиентки информацию о деятельности государственных, общественных организаций, оказывающих поддержку в решении значимых для нее вопросов. Поощряет совершать самостоятельные шаги, корректирует неверные действия. Необходимо отметить, что женщины в первые дни после освобождения часто дезориентированы в пространстве (не могут самостоятельно выстроить маршрут передвижения к месту нахождения социального учреждения, отказываются от использования нескольких видов общественного транспорта). Они не могут запомнить минимальную информацию, необходимую для передвижения и общения в государственных структурах, в связи с чем им рекомендуют записывать важные планируемые действия.

Это наиболее сложный период адаптации, от успеха которого часто зависит удержание от возвращения к преступному опыту и дальнейший личностный рост.

На этом этапе возможно включение в работу с клиенткой индивидуальных тренингов. В ходе тренинга моделируется ситуация посещения государственных и общественных организаций, доведение до должностных лиц своей позиции, проработка логичности предпринимаемых действий. При необходимости специалист совместно с клиенткой выезжает в местную командировку для посещения государственных (муниципальных) учреждений и личным примером показывает, как можно действовать для решения проблемы.

\section{Б) Социально-медицинские вопросы}

Как отмечалось выше, после 30-35 лет женщина начинает внимательнее относится к своему здоровью. О многих недостатках здоровья клиентка центра узнает в момент нахождения в условиях изоляции. Сложный путь принятия диагноза не всегда проходит безболезненно, с максимальным доверием к мнению специалиста исправительного учреждения. Таким женщинам надо помочь заговорить о проблемах своего здоровья, выстроить эффективные отношения с лечащим врачом, организовать контроль состояния здоровья на разных этапах социализации, добиться стабилизации физического и психического состояния.

Как правило, в первые посещения Кризисного центра в ходе доверительной беседы собирается информация о хронических заболеваниях, нахождениях в стационарных условиях лечебного учреждения, наличии инвалидности и ограничении трудоспособности в связи с перечисленными обстоятельствами. При наличии ВИЧинфекции женщина опрашивается о периодичности приема антиретровирусной терапии (далее - АРВТ). Специалист фиксирует отношение клиентки к своему здоровью и приему АРВТ. При необходимости намечается план действий по стабилизации состояния здоровья.

В ходе последующих встреч специалист центра поощряет самостоятельные шаги женщины по контролю за состоянием своего здоровья, корректирует действия клиентки по установлению диагноза, оказывает помощь в записи на прием к врачам-специалистам. Социальный работник разъясняет причины заболевания, характер его течения.

Дальнейшее общение по этому направлению ресоциализации связано с проведением мотивирующих бесед о здоровом образе жизни (далее - ЗОЖ), профилактике инфекций, передающихся половым путем (далее - ИППП), возрастных изменениях женского организма. В рамках данного направления работы специалистами оказывается помощь в преодолении наркозависимости.

В первые месяцы после освобождения нередко обострение многих заболеваний, не проявлявшихся до этого момента. Не желая справляться с трудностями, женщины потакают слабостям организма, манипулируют его ослаблением, когда ставится вопрос о необходимости трудоустроиться. Тем не менее, следует понимать, что от официального трудоустройства зависит успех встраивания человека в социальные отношения и возможность предотвращения рецидива преступления.

\section{В) Социально-трудовые вопросы}

Основная задача на этом этапе работы связана с достижением материальной независимости человека, освободившегося из мест изоляции.

Практика показывает, что первые самостоятельные 
шаги женщины, как правило, неверны. Это - трудоустройство по объявлениям в газете, по знакомству. Такие действия часто не гарантируют даже минимальной заработной платы. Имеет место шантаж и унижение со стороны работодателя, узнавшего о преступном прошлом работника.

Обладая низким уровнем образования, слабыми профессиональными навыками, самостоятельно женщины не могут трудоустроиться на протяжении 2-3 месяцев, не говоря об официальной работе. В настоящее время в условиях Санкт-Петербурга клиентки Кризисного центра работают преимущественно в сфере клининга, востребован труд швей, подменных продавцов, фасовщиков на разных производствах. Без дополнительного вложения материальных средств в образование шансы на успешное трудоустройство крайне низки.

Еще одной особенностью работы с клиентами является отсутствие документов, подтверждающих предшествующий трудовой стаж. Часто женщины не понимают важности официального трудоустройства, получения документов для организации последующей жизни, выплаты пособий и пенсий.

В первый месяц после выхода из колонии женщины испытывают трудности в выборе средств визуальной подачи себя, им нужна помощь в выработке уверенного речевого поведения и выбору сферы профессиональной деятельности. В силу низкого уровня правовой грамотности женщины нуждаются в юридическом сопровождении устройства на работу и консультировании по запросу на всех этапах трудовой деятельности.

\section{Г) Социально-педагогическая вопросы}

Успешность сопровождения во многом определяется степенью доверия между специалистом Кризисного центра и женщиной, испытывающей трудности в адаптации после освобождения из колонии.

Сразу после освобождения женщина остро нуждается в поддержке позитивных начинаний, социальноприемлемого поведения, упорядочивания отношений с детьми и социумом.

Отягощенные наркозависимостью женщины испытывают трудности в составлении примерного плана повседневных дел, выстраиванию взаимоотношений с собственным ребенком, не знают особенностей возрастных изменений в поведении детей.
Благодаря активному личному участию женщин среднего и молодого возраста в интернет проектах, сотрудниками центра организовано закрытое сообщество, где выкладывается актуальная информация, ведется работа по формированию позитивных интересов в сфере досуга.

Ситуация пандемии показала, что личное общение клиентки со специалистом центра обязательно в первые дни и месяц для взаимного узнавания, выстраивания контакта и выработки стратегии действий. В дальнейшем возможно поддержание отношений посредством страниц в социальных сетях с явкой в центр по конкретному запросу.

\section{Д) Социально-правовая вопросы}

Большинство женщин, обратившихся в Кризисный центр после освобождения из исправительного учреждения, отличаются низким уровнем правовой грамотности. Среди их проблем - долги за коммунальные услуги в период отбывания уголовного наказания, лишение/ восстановление родительских прав, отсутствие жилья или тяжбы с заинтересованными лицами о лишении прав на жилое помещение. Ориентируясь на потребности конкретной жизненной ситуации, специалисты центра ведут индивидуальные консультации для выработки действий по защите прав клиентки, решении ее материальных и бытовых проблем.

Таким образом, ресоциализация, как комплекс мер по профилактике преступного поведения, реализуемых социальным учреждением, направлена на расширение кругозора женщины, развитие ее интеллектуальных способностей, привитие устойчивых ценностных ориентиров, одобряемых в законопослушном обществе, стабилизацию физического и психического состояния после освобождения из исправительного учреждения и включает в себя педагогическую поддержку позитивных начинаний женщины, правовое просвещение, формирование у клиентки навыков эффективного взаимодействия с работодателем, продуктивного общения с представителями разных организаций, усвоение навыков самостоятельного преодоления трудностей бытового характера в рамках социально-одобряемого поведения, упорядочивание отношений с собственными детьми и обществом, достижение внутреннего равновесия.

Реализация перечисленных мер позволяет судить об успешности профилактической стратегии, избранной в отношении конкретной женщины, покинувшей исправительное учреждение. 


\section{ЛИТЕРАТУРА}

1. Уголовно-исполнительный кодекс Российской Федерации: [федер. закон от 8 янв. 1997 г. № 1-Ф3: принят Гос. Думой 18 дек. 1996 г.] // Собр. законодательства Рос. Федерации. - 1997. - № 2, ст. 198.

2. Уголовный кодекс Российской Федерации: [федер. закон от 13 июня 1996 г. № 63-Ф3: принят Гос. Думой 24 мая 1996 г.] // Собр. законодательства Рос. Федерации. - 1996. - № 25, ст. 2954.

3. 06 основах социального обслуживания граждан в Российской Федерации: федер. закон от 28 дек. 2013 г. №442-Ф3 // Рос. газ. - 2013. - 30 дек.

4. 06 основах системы профилактики правонарушений в Российской Федерации: федер. закон от 23 июн. 2016 г. № 182-Ф3 // Рос. газ. - 2016. - 28 июн.

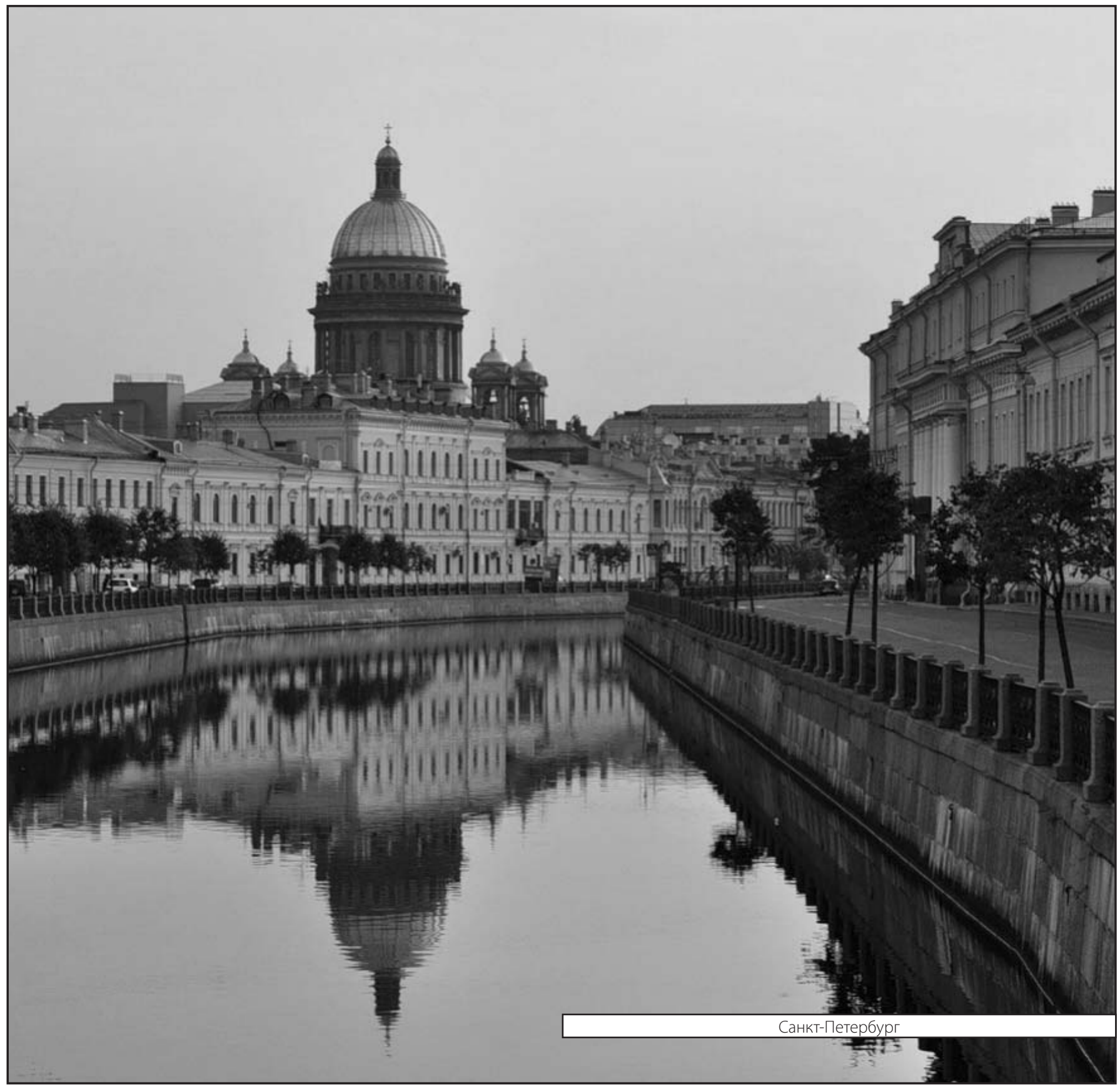

